\title{
GLOBALIZAÇÃO, TRANSNACIONALISMO, DIREITOS HUMANOS E JURISDIÇÃO TRABALHISTA: REFLEXÕES SOBRE O TRATAMENTO DE CONFLITOS LABORAIS NO CONTEXTO TRANSNACIONAL
}

\section{Danilo Scramin Alves ${ }^{1}$}

Resumo: A presente pesquisa estabelece um diálogo entre globalização, transnacionalismo, direitos humanos e a necessidade de uma jurisdição trabalhista que reconheça a conexão entre estas realidades, reconhecendo como a jurisdição trabalhista é impactada pela globalização e pela transnacionalização, a visão dos direitos trabalhistas como direitos humanos e o tratamento de conflitos trabalhistas transnacionais hodiernamente. Constatou-se que, apesar da transnacionalização dos conflitos, os Estados estão exercendo jurisdição como, bem como já se percebe a ocorrência de jurisdição transnacional em matérias trabalhistas, mesmo que a necessidade de um órgão jurisdicional transnacional trabalhista subsista. Trata-se de pesquisa qualitativa, exploratória e bibliográfica, de método indutivo.

Palavras-Chave: Globalização; Transnacionalismo; Direitos Humanos; Direitos Trabalhistas; Jurisdição Trabalhista.

\section{GLOBALIZATION, TRANSNATIONALISM, HUMAN RIGHTS AND LABOR JURISDICTION: REFLECTIONS ON THE TREATMENT OF LABOR CONFLICTS IN THE TRANSNATIONAL CONTEXT}

\begin{abstract}
This research establishes a dialogue between globalization, transnationalism, human rights and the need for a labor jurisdiction that understands the connection between these realities, recognizing how labor jurisdiction is impacted by globalization and transnationalization, the view of labor rights as human rights and the handling of transnational labor conflicts today. It was found that, despite the transnationalization of conflicts, States are exercising jurisdiction, as well as the occurrence of transnational jurisdiction in labor matters is already noticeable, even if the need for a transnational labor jurisdiction remains. It is a qualitative, exploratory and bibliographical research, using an inductive method..
\end{abstract}

Keywords: Globalization; Transnationalism; Human Rights; Labor Rights; Labor Jurisdiction.

\section{INTRODUÇÃO}

$\mathrm{Na}$ atualidade, é possível perceber um processo de ampliação das relações humanas, aí incluídas as sociais, as econômicas e as trabalhistas, o que faz com que os limites nacionais e de soberania dos Estados sejam cada vez mais diminuídos, em uma transição

\footnotetext{
${ }^{1}$ Doutorando em Ciência Jurídica pela Universidade do Vale do Itajaí/UNIVALI, em regime de cotutela, com dupla titulação junto à Università degli Studi di Perugia, Itália. Mestre em Direito pela Universidade de Marília/UNIMAR. Especialista em Direito e Processo do Trabalho pela Universidade Anhanguera, em Direito do Consumidor e em Ensino da Língua Inglesa pela UniBF e em Gastronomia pela Pontifícia Universidade Católica do Rio Grande do Sul. Professor do curso de Direito do Centro Universitário Uninorte de Rio Branco/AC. Analista Processual do Ministério Público do Estado do Acre.
} 
cientificamente conhecida como globalização.

Um dos efeitos desse processo é a transnacionalização dos conflitos, o que faz com que os modelos tradicionais de mecanismos de solução desses conflitos, em especial a jurisdição, se tornem relativamente ineficazes sem adequações em direção a esse novo modelo. Ainda assim, conflitos e infrações aos direitos humanos e trabalhistas ocorrem, talvez até em uma maior proporção diante da expansão das relações a um nível supranacional e por vezes até global.

O objetivo da presente pesquisa é identificar como esses eventos se comunicam, em busca da definição de como os conflitos trabalhistas podem e vêm sendo solucionados, principalmente pela jurisdição, nesse contexto de transnacionalismo avançado.

Para tanto, primeiramente, será feita uma análise da globalização enquanto instituto que tem impacto direto nas relações humanas. Em seguida, será estabelecido como o processo de transnacionalização vem sendo casado às questões de direitos humanos e de direitos trabalhistas. Por fim, se discorrerá sobre como a jurisdição trabalhista pode garantir esses direitos e como, face à transnacionalização das relações causada pela globalização, impacta nessa jurisdição, sendo, portanto, também transnacionalizada.

A pesquisa desenvolvida tem como modelo o teórico-qualitativo, com abordagem exploratória, tendo como base o método indutivo, a partir de uma revisão bibliográfica, sendo que, para o tratamento dos dados, foi utilizado o método cartesiano.

\section{CONCEITOS, CARACTERÍSTICAS E EFEITOS DA GLOBALIZAÇÃO}

Com o objetivo de alcançar a compreensão sobre globalização capaz de fundamentar todo o caminho teórico-crítico proposto no presente artigo, realizar-se-á uma breve explanação acerca do conceito de pós-modernidade calcada nas obras de Anthony Giddens, para então, a partir do conceito apresentado pelo referido autor, estabelecer uma dinâmica de diálogo entre Giddens e outros autores que também são referências quando se trata da temática. Ademais, analisar-se-á a intersecção entre a globalização e a demanda de uma visão transnacional para a resolução das demandas sociais.

A importância de compreender no que consiste a pós-modernidade diz respeito ao fato de que, no desenvolvimento de uma nova concepção de sociedade, bem como do nascimento de instituições que atendam as demandas advindas da referida ordem social que 
emerge, fica evidente que estar em permanente disparidade com o passado se refere a algo diferente, sendo que "uma nova agenda social e política surgiu com a crescente proeminência de preocupações ecológicas e talvez de novos movimentos sociais em geral. Dificilmente alguém hoje em dia parece identificar a pós-modernidade com o que ela tão amplamente já chegou a significar" (GIDDENS, 1991, p. 46).

O conceito de globalização é demasiadamente complexo. A fim de explicitar este fato, o autor apresenta duas perspectivas conceituais sobre o mesmo fenômeno, visto que este leva a ampliação das relações sociais à nível global. Com efeito, tem-se a aproximação de "localidades distantes", pois episódios antes de efeitos meramente locais acabam sofrendo alterações em sua estrutura, já que reverberam em distâncias anteriormente nunca pensadas e vice-versa. É por essa razão que, na visão de Vandresen e Souza (2016, p. 3), a globalização tem ido em direção a uma ruptura de paradigmas que afetam diretamente o Estado nacional.

O contexto supramencionado clarifica a dinâmica dialética estabelecida entre eventos locais cujo efeito pode alcançar uma direção diversa das relações que mesmo distantes seriam vistas de forma paradigmática. Para Giddens (1991, p. 60), o efeito de modificação local vem tanto em razão da própria globalização como da extensão horizontal das ligações entre pessoas, incluindo especialmente as negociações e dinâmicas econômicas mundiais.

Vandresen e Souza (2016, p. 4) relatam, a partir das próprias lições de Giddens, que são propulsores da globalização a expansão das comunicações globais, o desenvolvimento de um modelo de economia global (evidenciado por empresas transnacionais), mudanças políticas e o surgimento e implementação de mecanismos regionais e governança internacional.

Giddens apresenta quatro dimensões da globalização, a saber: (I) Economia capitalista mundial, (II) Sistema estado-nação; (III) Ordem militar; (IV) Divisão internacional do trabalho, mas aponta ao mesmo tempo que há um aspecto por trás dessas dimensões institucionais, ao qual chama de globalização cultural, resultado do impacto das tecnologias mecanizadas de comunicação, que fazem com que as pessoas tenham acesso a informações globais, possibilitando a extensão atual das instituições da modernidade (GIDDENS, 1991, p. 73).

Neste contexto, considera-se que o denominado fenômeno da globalização detém como traço marcante a multiface de interesses: ao passo que configura uma cadeia estatal, social e de interesses hegemônicos, também compõe uma teia de conflitos sociais, estatais e 
interesses subalternos; dentro dos quais, mesmo nas relações com interesses hegemônicos, possuem ramificações (SANTOS, 2002, p. 27).

Nesse sentido, conforme indica Piffer (2014, p. 10), a globalização se trata de um fenômeno robustecido originalmente no capitalismo neoliberal, com fundamento tipicamente econômico que floresce a partir da noção de integração entre economias nacional e internacional dentro da realidade mercantil mundial.

Foi a partir dessa percepção que Cruz e Bicca (2018, p. 8) indicam que a Globalização é, em suma, responsável por criar uma verdadeira rede de conexões temporais e territoriais, dentro das quais forma-se um intenso vínculo entre indivíduos e fenômenos longínquos, relacionando-se logo às concepções de internacional ou internacionalização.

Nesses termos, Cruz e Bodnar (2009, p. 20) apontam que o mundo vivencia um célere processo de mutação a uma inédita estrutura planetária, que deve ter seu efetivo funcionamento alicerçado em relações solidárias e integrativas, uma vez que o anseio utópico tradicionalmente é o que o orienta e atribui significado às construções humanas.

A realidade é que a globalização é fato e vem sendo amplamente discutida. Giddens (2006, p. 50) vem recentemente reconhecendo que o termo globalização tem sido usado, com certa consistência e em muitas instâncias diferentes, por políticos, acadêmicos, empresários e pela mídia, tornando-se assim uma palavra comum no vocabulário do público, e o ideal por trás desse conceito é que, conforme descrito, como as pessoas vivem no mesmo planeta, suas nações, governos e sociedades, e consequentemente os sistemas jurídicos, se interconectam e se tornam interdependentes.

Esse processo naturalmente traz uma série de fragilidades não apenas nas relações humanas, mas também nos demais campos da existência. Exemplo de reflexo negativo dessa globalização é a crise ambiental global descrita por Estenssoro Saavedra (2019, p. 21) como resultado do processo de desenvolvimento econômico e de padrão de vida dos países do norte, que além de ter o impacto nocivo na Terra, inviabiliza similar crescimento no sul.

Outro reflexo que pode ser observado de forma mais concreta e física é o alastramento da COVID-19 e seu consequente caos real, mundial, similar, concomitante, novo e que afetou e continua a afetar os direitos humanos, sociais e econômicos. Tão rápida quanto o próprio alastramento da doença foi a disseminação das (poucas) informações a ela referentes e os resultados na saúde mundial. A instabilidade econômica e política consequente também foi globalizada quase imediatamente. 
Logo, se apresenta imprescindível salientar que o fenômeno da globalização passou a ter importância inegável em diversas áreas da vida dos sujeitos sociais

A leitura que se procura fazer a partir do presente artigo, qual seja, da análise do processo de solução de conflitos trabalhistas no atual contexto, depende do reconhecimento de que os trabalhadores estão no cerne das mudanças mais recentes causadas e observadas em razão da globalização.

Friedman (2002) aponta que, ao menos superficialmente, o objeto da globalização é o comércio. Hill (2013, p. 45) destaca que, em um nível mais profundo, o objeto real da globalização são as próprias pessoas, por meio de sua cultura, relações sociais e trabalho.

Isso porque, a partir dos exemplos trazidos, a degradação ambiental e a consequente fragilização econômica por ela causada têm impacto direto nas relações trabalhistas, seja pelo fato de que, dentre as várias concepções de meio ambiente reconhecidas e afetas pela crise ambiental global, não se pode separar o meio ambiente de trabalho.

Quanto à COVID-19, é inegável o impacto nas relações trabalhistas. Primeiramente, o massivo impacto econômico resulta diretamente na reorganização, muitas vezes na direção da indesejável extinção, das relações de trabalho. Em segundo lugar, aquelas posições laborais mantidas sofrerão a degradação ambiental laboral consequente de uma pandemia. Todo e qualquer lugar em que há movimentação de pessoas, aí necessariamente incluído o ambiente laboral, se torna um possível local de contaminação.

Ante este contexto, somado com a sempre propagada preocupação dos órgãos internacionais oficiais para que se preserve o contexto humanitário na execução dos deveres dos trabalhadores dentro do mundo abraçado pela demandas capitalistas, finaliza-se a presente proposta utilizando o método socrático, consequentemente indagando: os fatos vivenciados e relatados cotidianamente não são suficientes para que os grupos responsáveis por pensar e regulamentar as melhores condições de trabalho - aqui pensada como a efetivação da dignidade da pessoa humana de cada um desses indivíduos, aos menos levando em consideração os efeitos mais gerais "comuns" -, comecem a elaborar protocolos prevendo políticas públicas de tratamento, ou a preocupação com os sujeitos que sofrem os reflexos do mundo globalizado é mais uma hipocrisia legalmente assegurada que não passará de letra morta e discurso meramente retórico?

O resultado dessa inquietante reflexão tem que ser globalizado tal qual o problema para o qual se busca uma resposta no momento. Não há como reconhecer o caráter 
globalizado as relações humanas e o seu impacto nas relações de trabalho sem que globalize também os métodos e os meios de solução de conflitos trabalhistas, os mecanismos de proteção e reconhecimento dos direitos trabalhistas e a necessária preservação dos trabalhadores enquanto seres humanos.

Nesse sentido, há de se falar não apenas dos reflexos negativos da globalização, mas também do resultado mundial das relações humanas conhecida como transnacionalismo, cuja proposta poderá, até certo ponto, responder à indagação feita.

\section{UMA ANÁLISE DO TRANSNACIONALISMO NO CONTEXTO DE EFETIVAÇÃO DOS DIREITOS HUMANOS E TRABALHISTAS}

A fim de descrever da forma mais clara possível cada um dos temas abordados, farse-á uma análise acerca da essência presente no processo conhecido como transnacionalização, buscando compreender seu conteúdo e possíveis efeitos sociais, com foco na busca pela resposta da problemática proposta neste trabalho dada sua evidente conexão com a efetivação dos Direitos Humanos em escala supranacional.

Dentre os fenômenos que emergem como reflexo da globalização, ressalta-se a denominada transnacionalização, caracterizada pela desterritorialização dos relacionamentos político-sociais, consolidado pelo capitalismo ultra valorizado, que orienta o ordenamento jurídico global acerca das soberanias estatais.

Nesse contexto, a transnacionalidade é incorporada ao cenário globalizado, indo além do estatal, transpassando-o; delineando a diferença entre globalização e transnacionalidade: ao passo que a primeira remete à concepção de conexão global, universalidade; esta última refere-se à ideia de "Estado permeável", com decrescente valorização estatal (STELZER, 2011, p. 21).

$\mathrm{Na}$ condição delineada, a transnacionalização se revela como fenômeno complexo, heterogêneo e controverso, na medida em que encontra objeções para ser tratada como algo habitual e natural na realidade. A título exemplificativo, pode-se citar a desterritorialização dos vínculos humanos e de produção, bem como o capitalismo exacerbado que expressa a economia transnacionalizada e a emergente instabilidade da soberania estatal, sobrevindo novos atores nesta contemporânea trama mundial (STELZER, 2011, p. 25).

Ademais, a desterritorialização é também uma das principais expressões da 
transnacionalidade, porquanto trata-se de questões que ultrapassam as noções fronteiriças e estatais, revelando-se no transpasse das fronteiras dos Estados (STELZER, 2011, p. 25). Logo, a transnacionalização é caracterizada especialmente por não se ater ao espaço territorial, tampouco à convencional noção de Nação Jurídica, antes reconhece e aceita a diversidade e os valores de cunho coletivo, consensual (CRUZ; BODNAR, 2009, p. 10).

Finalmente, o ordenamento jurídico constituído nesta conjuntura transnacional figura como um arranjo sistematizado, com sentido axiológico comum, dada a natureza global, que considera o todo, inalcançável na perspectiva nacional, internacional e societária (CRUZ; BODNAR, 2009, p. 15).

Apreender a concepção presente no processo proposto pelo transnacionalismo se apresenta fundamental, já que a efetivação dos direitos humanos, especialmente a dignidade da pessoa, os quais são os objetivos precípuos da jurisdição trabalhista, poderá ser mais bem discutida, instituída e implementada, caso se passe a olhar a humanidade e não o cidadão de determinado estado-nação.

A ligação entre os direitos humanos, principalmente da dignidade da pessoa, e a jurisdição trabalhista é clara e direta: os direitos trabalhistas pleiteados judicialmente têm sido sistematicamente reconhecidos pelos estudiosos especializados, a exemplo de Mantouvalou (2012), como direitos humanos fundamentais em si.

Consoante a isso, deve-se reconhecer que o objetivo máximo da prestação de serviços a título de trabalho é o recebimento de remuneração, por meio exclusivo da qual será possível a existência digna no atual contexto de transnacionalização capitalista avançada.

Ou seja, ao se falar em jurisdição trabalhista, está-se a falar, necessariamente, de direitos humanos e de dignidade da pessoa.

Sobre a dignidade da pessoa, Sarlet (2011, p. 22) entende que é elemento indissociável da própria condição de ser humano, devendo ser "reconhecida, respeitada, promovida e protegida, não podendo, contudo [...] ser criada, concedida ou retirada (embora possa ser violada), já que reconhecida e atribuída a cada ser humano como algo que lhe é inerente".

Além disso, na direção dos direitos humanos e da dignidade da pessoa no contexto do processo de transnacionalização, é possível relatar que é no âmbito dos direitos humanos que a interdependência das relações, característica do transnacionalismo, é fortemente delineada; uma vez que, para Ferrer e Cruz (2010, p. 11), a universalidade desses direitos é 
garantida tão somente quando ultrapassados os limites das concepções limítrofes modernas estatais da Democracia.

Por outro lado, vivencia-se um contexto transnacional que imprescinde da defesa de um mínimo de direitos a serem resguardados diante de um cenário de despotismo e desigualdade social intensa. Isso porque, as questões ligadas às demandas humanas são indispensáveis, especialmente, quanto à efetividade dos denominados Novos Direitos, os "direitos difusos e transfronteiriços". A título de exemplo, Piffer (2014, p. 181) cita as políticas de Imigração aplicadas aos Transmigrantes, carentes de uma concepção que considere a individualidade desses casos, orientada a reconhecer a natureza do Ser Humano e a defesa e proteção dos seus direitos.

A realidade, contudo, revela sua verdadeira face ao vislumbrar situações de desamparo de indivíduos humanos que dotam do transnacionalismo, os chamados Transmigrantes, que demandam o amparo de direitos ainda não reconhecidos como Novos Direitos, ou imediatamente desprezados, nos termos do antigo Estado soberano dos moldes da Idade Moderna. Desta feita, abdicar os traços transnacionais dos Direitos Humanos significa impossibilitar a proteção e legitimação dos direitos dos Transmigrantes nas mais diversas esferas. Por essa razão, Santos (1997, p. 122) acredita que, "na forma como são agora predominantemente entendidos, os direitos humanos são uma espécie de esperanto que dificilmente se poderá tornar na linguagem quotidiana da dignidade humana nas diferentes regiões do globo".

Em contrapartida, deve-se esclarecer que as questões transnacionais ultrapassam os debates sobre globalização econômica. Certo é que estão muito mais relacionadas aos direitos concernentes à continuidade da vida humana na terra. Não obstante seja a globalização econômica um dos cernes das demandas transnacionais, seu fundamento encontra-se na proteção da vida humana, bem como do ambiente em que as pessoas habitam (GARCIA, 2011, p. 175).

Nesse sentido, também emerge a discussão em torno da titularidade dos direitos fundamentais dentro do panorama transnacional, afinal, nascendo o cidadão transnacional, fragiliza-se a ideia daquele cujo nascimento em determinado lugar determina sua nacionalidade, gerando núcleos de pessoas privilegiadas pelo local e circunstâncias de nascimento, e pobre, os quais são, com base em Bauman (2001, p. 93/94), os turistas, dotados de mobilidade, passaportes e vistos, e os vagabundos, limitados aos locais degradados em que 
estavam e até muitas vezes expulsos, tornando-se refugiados e apátridas.

Nesse contexto, se por um lado é perceptível a enorme modificação no modo como se entende o Direito, por outro é indubitável que a transnacionalização deve ser associada à defesa dos direitos fundamentais, à liberdade garantida em consonância com a igualdade perante a lei. Em síntese, a transnacionalização do Direito deve ser aplicada de forma a efetivamente assistir os titulares dos direitos fundamentais, visto que, conforme Santos (1997, p. 122), "seja como for, o importante é não reduzir o realismo ao que existe, pois, de outro modo, podemos ficar obrigados a justificar o que existe, por mais injusto ou opressivo que seja".

A questão pode e deve ser analisada também sob a ótica das questões trabalhistas. Naturalmente, à medida que a mão-de-obra é utilizada, surgem as possibilidades de conflito, seja ele individual ou coletivo. Esses conflitos trabalhistas devem então ser tratados correta e prontamente, especialmente porque os direitos trabalhistas, conforme dito, têm sido sistematicamente reconhecidos como direitos humanos. O resultado é que os direitos das pessoas que trabalham em contextos transnacionais estão entre as questões jurídicas, incluindo os retromencionados direitos humanos, que constituem a necessidade de uma lei transnacional, ou pelo menos um sistema de jurisdição para conflitos transnacionais.

Outro aspecto direto da globalização é, então, a internacionalização das leis e dos sistemas jurídicos, que resultou no que hoje se denomina direito internacional. Nesse sentido, Jessup (1965, p. 12) prefere usar o direito transnacional para se referir e incluir todas as normas que regulam atos ou fatos que transcendem as fronteiras nacionais. Assim, optou-se por usar esta mesma nomenclatura para o presente estudo.

Ademais, no que diz respeito ao compromisso de os direitos humanos e sua proteção transnacional se fazerem presentes no ambiente de trabalho, Piovesan (2013, p. 189) salienta que:

Ao lado do Direito Humanitário e da Liga das Nações, a Organização Internacional do Trabalho (International Labour Office, agora denominada International Labour Organization) também contribuiu para o processo de internacionalização dos direitos humanos. Criada após a Primeira Guerra Mundial, a Organização Internacional do Trabalho tinha por finalidade promover padrões internacionais de condições de trabalho e bem-estar. Sessenta anos após a sua criação, a Organização já contava com mais de uma centena de Convenções internacionais promulgadas, às quais Estados-partes passavam a aderir, comprometendo-se a assegurar um padrão justo e digno nas condições de trabalho. 
Com efeito, a fim de responder o questionamento que delineou a construção lógica deste ponto, constata-se que a literatura especializada em direitos humanos deixa clara a abrangência e relevância do tema relativo à proteção dos trabalhadores, que necessitam de um outro olhar sobre as demandas essenciais capazes de garantir sua dignidade. Logo, pode-se afirmar que um tratamento sobre a questão trabalhista com base numa perspectiva transnacionalista seria rico, pois, a soma de um conjunto de problemas similares pode encontrar respostas também similares e resultados mais vantajosos.

A percepção à qual se pode chegar é que, uma vez reconhecido que uma consequência da globalização e da expansão internacional do comércio causou a transnacionalização do trabalho, um sistema de leis trabalhistas transnacionais e jurisdição trabalhista transnacional deve ser implementado também, de modo a abranger os trabalhadores que foram levados a esses tipos das condições de trabalho e resguardar seus direitos enquanto direitos humanos.

Assim, faz-se necessário analisar a jurisdição trabalhista enquanto forma de tratamento de conflitos entre trabalhadores e empregadores, em especial nesse contexto de transnacionalismo avançado, isto é, em relações trabalhistas transnacionais, o que será feito a seguir.

\section{A JURISDiÇÃo TRABALHISTA TRANSNACIONAL COMO FORMA DE TRATAMENTO DE CONFLITOS}

A partir dessa constatação, duas análises separadas e bastantes distintas da adequação pela qual devem passar as percepções jurídicas dessas relações de trabalho podem ser feitas.

A primeira é sobre quais são os direitos dos trabalhadores aplicáveis aos contratos transnacionais, considerando que esses contratos normalmente abrangem vários sistemas jurídicos, todos os quais provavelmente com legislações trabalhistas diferentes e por vezes opostas. Na verdade, a própria variação das normas trabalhistas de país a país pode ser problemática.

O reconhecimento da dificuldade causada pela discrepância normativa dos sistemas jurídicos, conforme relata Doorey (2010, p. 959), a Constituição original da Organização Internacional do Trabalho - OIT, instituída por meio do Tratado de Versalhes em 1919, afirmava que se uma nação não obtivesse condições humanas de trabalho, isso se tornaria um 
obstáculo para todas as outras nações que esperam fazê-lo em suas próprias soberanias.

Isso fez com que os países às vezes tentassem influenciar outras nações a seguir seu próprio exemplo na aplicação de legislações trabalhistas iguais ou semelhantes às suas, rotuladas por Doorey (2010, p. 955) como "regulamentação trabalhista doméstica transnacional", que significa "legislação promulgada em um país que se destina a influenciar as práticas trabalhistas em outros países", sendo que existem até duas formas diferentes pelas quais essa influência pode acontecer, incluindo o apoio a vínculos diretos entre comércio e trabalho em acordos comerciais regionais e supranacionais e medidas de soft law destinadas a recompensar as práticas de trabalho decentes e punir as ofensivas, e a promulgação unilateral de legislação com o objetivo de influenciar as práticas trabalhistas em jurisdições estrangeiras.

Não é incomum também que se busque uma influência enquanto inspiração constitucional da tutela e da defesa dos direitos trabalhistas, na medida em que direitos humanos e sociais normalmente encontram guarida nas constituições dos sistemas jurídicos.

Assim, mesmo que a Constituição de um determinado Estado não preveja diretamente normas trabalhistas reconhecidas por outros países, no momento da necessária, na leitura de Tribe e Dorf (2020, p. 77), interpretação e reinterpretação constitucional na interminável busca por sua compreensão, podem os demais sistemas jurídicos servir de inspiração hermenêutica.

No entanto, persistem as diferenças nos sistemas jurídicos, causadas por diferenças na cultura, economia e política que podem ser percebidas entre as nações. Assim, não é incomum que múltiplas possibilidades de diferentes legislações trabalhistas sejam potencialmente aplicáveis ao mesmo trabalhador ou grupo de trabalhadores. Isso, como apontam Lara e Goulart (2013), levanta a questão de qual é a lei aplicável, ou qual norma deve prevalecer.

Martins (1999) revela que muitas perspectivas podem ser utilizadas para estabelecer qual a lei que deve ser utilizada, como, por exemplo, a lei do local do empregador, do local de celebração do contrato, do local de onde vêm as regras, do local de onde os salários vinham, o idioma do contrato ou a nacionalidade dos envolvidos, ou mesmo uma combinação de alguns deles. Porém, utilizando o princípio da proteção ao trabalhador que é um dos fundamentos do direito do trabalho brasileiro, o autor elaborou a diretriz de que a lei mais favorável pode trazer ao trabalhador as melhores vantagens, indo ao encontro do objetivo de real justiça.

Apesar da falta de concretude de definição, esse entendimento vem sendo bem aceito 
doutrinariamente, apesar das diversas modificações e normativas que impactam, no Brasil, na questão referida, como a já cancelada Súmula no 207 do Tribunal Superior do Trabalho, que estabelecia a regra da lei do local da prestação do serviço, e o art. $9^{\circ}$ da Lei de Introdução às normas do Direito Brasileiro, que coloca como regra as normas do local de assinatura do contrato.

Com mudança na legislação feita pela Lei n. ${ }^{\circ}$ 11.962/2009, que alterou a Lei n. ${ }^{\circ}$ 7.064/82, o entendimento descrito foi normatizado, de forma a estabelecer no ordenamento jurídico que a legislação brasileira será utilizada no lugar da legislação do país em que ocorreu o trabalho se as leis brasileiras forem mais benéficas ao trabalhador.

O segundo problema levantado pela transnacionalização do trabalho, se a questão de qual é o sistema jurídico cujas normas devem ser usadas for de alguma forma respondida, é qual é a jurisdição que será usada para reforçar a legislação que foi decidida como apropriada para o caso.

A resposta possível atual para essa questão pode ser construída a partir da perspectiva de um país específico, como o Brasil. No entanto, considerações em relação a uma jurisdição transnacional, dado o contexto atual descrito, devem ser levantadas.

Já é possível observar, dentro da ciência jurídica, diversos e necessários estudos sobre um modelo transnacional de jurisdição transnacional, muitas vezes para tratar de forma específica os conflitos trabalhistas. Na medida em que as relações de trabalho e contratos de prestação de serviços se tornam internacionalizados, a ideia anteriormente prevalente de sistemas jurídicos tradicionais com o exercício jurisdicional focado em cada Estado individualmente se tornou insuficiente para lidar com os conflitos que surgiam, o que exigiu que cientistas jurídicos apresentassem uma nova teoria que pudesse contornar tal problema.

Vandresen e Souza (2016), em atenção a esse fenômeno que se torna a cada dia mais observável em uma sociedade transnacional e globalizada, discorreram sobre essa possibilidade de jurisdição transnacional, especialmente no que se refere aos direitos humanos, referindo-se a proposições científicas já existentes que poderiam ser utilizadas, citando o transconstitucionalismo como exemplo.

A transnacionalização do exercício jurisdicional não é um processo fácil, elas deixam claro, mas é uma resposta viável e concreta e que já começou a ser posta em prática.

Berger-Walliser (2018, p. 1.303) aborda a mesma problemática referente às lides que superam as barreiras nacionais, direcionando a sua possível solução a um dever de 
harmonização dos sistemas jurídicos por meio de normas acordadas internacionalmente, o que deve permanecer uma prioridade. Essas normas ajudariam a combater a procura de tribunais, assim como evitariam conflitos e poderiam resolver questões urgentes sobre quais as cortes nacionais deveriam ter que se pronunciar ao julgar empresas multinacionais. Se existissem normas de jurisdição transnacional, é possível concluir, esses problemas não existiriam.

Similarmente, Koh (1996, p. 184) defende a criação de um processo legal transnacional, que seria a teoria e prática de como agentes internacionais ou internacionalizados, como Estados-nação, organizações internacionais, empresas multinacionais, organizações não governamentais, e indivíduos privados que com eles contratem, interagem em uma variedade de tribunais, públicos e privados, nacionais e internacionais para fazer, interpretar, fazer cumprir e, em última instância, internalizar as regras do direito transnacional.

Na mesma direção, mas com uma proposta diferente, Simowitz (2018) defende que os Congressos dos países deveriam envidar esforços para que o Poder Legislativo de cada nação reconhecesse, dentro de sua legislação, a jurisdição transnacional.

No Brasil, esse tipo de pesquisa e direcionamento também já pode ser observado. Hill (2013) critica a ausência de tradição transnacional no sistema brasileiro de direito processual civil, o que resulta numa inafastável limitação do acesso à justiça motivada pelo número crescente de relações transnacionais, razão pela qual propõe um microssistema processual civil que é transnacional, criado em atenção aos direitos humanos e o processo constitucional, inspirado principalmente pelo modelo de jurisdição transnacional que é observado na União Europeia.

Com a ausência de modelos propriamente transnacionais amplamente difundidos, acessíveis e reconhecidos pelos ordenamentos jurídicos nacionais, ainda se mantém a necessidade de se tratar os conflitos transnacionais, incluindo os trabalhistas.

No Brasil, essa missão, para questões trabalhistas, é levada à Justiça do Trabalho, cuja competência, estabelecida na Constituição, em seu art. 114, tem inserida a possibilidade de julgamento de relações trabalhistas, incluindo aquelas em que figure como parte entes de direito público externo. Essa competência já está reconhecida desde a promulgação da Constituição em 1988.

Nos termos do art. 651 da CLT, em seu parágrafo segundo, as ações que envolvam conflitos trabalhistas que surjam em empregadores localizados no estrangeiro também serão 
de competência da Justiça do Trabalho brasileira, desde que o trabalhador seja brasileiro, o empregador tenha pelo menos representação no Brasil e não exista convenção internacional que impeça a ação.

É interessante apontar, porém, que recentemente alguns desses requisitos têm sido mitigados, com o interesse de garantir acesso à justiça e efetividade da jurisdição, razão pela qual, por exemplo, estrangeiros podem, em alguns casos, ajuizar reclamação trabalhista no Brasil. Além disso, a norma não estabelece requisitos relacionados ao local da prestação do serviço, do domicílio do trabalhador ou da contratação

A lei não determina o local cuja vara do trabalho será competente para julgar a ação, mas a doutrina especializada (ALVES, 2020, p. 99) vem reconhecendo, em atenção aos princípios processuais da proteção mitigada ao trabalhador e do acesso à justiça, que o empregado pode optar por uma de três possibilidades: na cidade de residência do trabalhador, se for no Brasil; na cidade da celebração do contrato, se isso aconteceu no Brasil; ou no lugar de representação, sucursal, agência ou escritório do empregador no Brasil.

Há grande debate sobre a questão da imunidade dos Estados estrangeiros e organismos internacionais, sendo que, conforme relata Lupi (2011), a resposta a esse problema tem se modificado ao longo do tempo.

Atualmente, se reconhece no Brasil a inexistência de imunidade de jurisdição de outros países para outros países, mas com a limitação referente à imunidade de execução. Nesse sentido, o julgamento do Recurso Extraordinário n 222.368/PE pelo Supremo Tribunal Federal. Para os organismos internacionais, o Tribunal Superior do Trabalho estabeleceu, por meio da Orientação Jurisprudencial $n^{\circ}$ 412, que organismos internacionais têm imunidade, desde que esteja prevista em um tratado ou convenção internacional ao qual o Brasil é signatário, e desde que o organismo não tenha expressamente renunciado este privilégio.

É importante destacar, enquanto contraponto, a lição trazida por Caetano (2016, p. 395/396), que reconhece que a imunidade, tanto de jurisdição quanto de execução, das organizações internacionais não pode ser aplicada se não houver outra forma de resolução do conflito, caso contrário representaria uma limitação injusta ao acesso à justiça.

Caetano (2016, p. 397/398) faz duas advertências: 1) se for retirada a imunidade de execução, a constrição dos bens nunca deve ser pelo uso da força, entrando à força na unidade da entidade estrangeira; e 2) se o Brasil faz parte do organismo internacional, não seria correto manter a imunidade de jurisdição, sendo mais desejável que a responsabilidade 
recaísse sobre o próprio Brasil.

Lupi (2011) afirma que a Justiça do Trabalho brasileira causou a "rachadura no muro da imunidade" e ainda é a instância jurisdicional mais ativa no Brasil em relação aos conflitos transnacionais. Esse fato confirma a importância da possibilidade de jurisdição que é reconhecida pelo ordenamento jurídico brasileiro aos seus tribunais do trabalho no que se refere aos processos transnacionais, como forma de garantir os direitos sociais dos trabalhadores.

Porém, alguns modelos reais de jurisdição transnacional para tratar especificamente de questões trabalhistas, sejam relacionadas a direitos sociais ou à proteção do trabalho, já podem ser observados, e, considerando o tema da presente pesquisa, é interessante colacionar alguns destes exemplos.

Em primeiro lugar, quando se fala em jurisdição transnacional trabalhista, é natural que se pense sobre a Organização Internacional do Trabalho - OIT. A OIT possui um sistema próprio de apreciação de queixa e reclamações, muitas vezes apresentadas por Estadosmembros contra outros Estados-membros, e apreciadas por órgãos internos, de acordo com a matéria trabalhista principal da Convenção ou Recomendação supostamente desrespeitada (PIMENTA, 2015, p. 247).

A Organização Mundial do Comércio possui um sistema próprio de tratamento de conflitos, cujo objetivo, nas palavras de Silva (2015, p. 200), “é reforçar a observância das normas comerciais multilaterais e a adoção de práticas compatíveis com os acordos negociados", sendo um mecanismo não punitivo, direcionado a possibilitar acordos entre as partes conflitantes, e que possui um órgão de apelação, que funciona como instância revisora.

A Corte Internacional de Justiça também pode exercer jurisdição sobre questões trabalhistas. Conforme relata Ribeiro (2015, p. 328), a referida Corte tem atuação em casos como de escravidão e trabalho forçado, com o objetivo de cessação da violação, busca pela não repetição, reparação e contramedidas, apesar de ter limitações representadas pela soberania dos Estados.

A questão do trabalho escravo e forçado, por sinal, caracteriza crime contra a humanidade, sendo reconhecidamente um crime processado e condenado inclusive internacionalmente. Assim, órgãos de jurisdição criminal internacional terão atuação em casos dessa natureza, assim como em outros casos de crimes relacionados com questões trabalhistas, como a exploração do trabalho infantil. 
Moreira e Ferreira (2015, p. 340) relatam, a título de exemplo, a possibilidade de jurisdição do Tribunal Penal Internacional para casos que envolvam trabalho escravo, ainda que reconheçam certas limitações na responsabilização.

Também é possível ainda que blocos econômicos regionais, tais quais o Mercosul e a União Europeia, estabeleçam, dentro de suas estruturas, órgãos dotados de jurisdição, que atuarão em casos de conflitos trabalhistas. A título de exemplo, Moreira (2015, p. 300/301) relata que o Tribunal de Justiça da União Europeia possui atuação em casos que tratem de direitos trabalhistas inseridos nos direitos da União Europeia, ainda que com algumas particularidades.

Por fim, cabe destacar que, conforme descrito anteriormente, os direitos dos trabalhadores também são direitos humanos. Esse reconhecimento é essencial tendo em vista a prevalência de órgãos de jurisdição transnacional que, por essa razão, também atuarão em casos de conflitos trabalhistas.

Assim, como exemplo, o Sistema Interamericano de Proteção dos Direitos Humanos atua em casos relacionados a direitos sociais, econômicos e trabalhistas, ainda que Ávila (2015, p. 222-223) entenda que essa atuação seja incipiente e ainda exista debate doutrinário sobre o melhor meio de exercício desse modelo de jurisdição. Por outro lado, Santos e Nicoli (2015, p. 254/255) entendem que casos de matérias trabalhistas já foram tomados anteriormente, tendo, inclusive, as decisões força vinculante e obrigatória no Brasil.

Baratto (2015, p. 272) relata que a Corte Europeia de Direitos Humanos já atuou, pela integração dos conceitos referentes à jurisdição da Corte e de Direitos Humanos, em casos de matéria trabalhista, mas que também já houve negativa de prestação jurisdicional, o que expõe um problema a ser solucionado.

Assim, constata-se que a questão da jurisdição transnacional trabalhista já é uma realidade, seja pela atuação dos Estados-nação como o Brasil em casos que envolvam labor transnacional, seja pela atuação de órgãos já estabelecidos que, ou atuam em prol da proteção do trabalho, como a OIT, e portanto acabam por realizar atividades de pacificação de conflitos, ou são dotados de jurisdição transnacional e, mesmo que essa jurisdição não seja trabalhista, acabam por julgar também matérias relacionadas ao trabalho.

\section{CONSIDERAÇÕES FINAIS}


A presente pesquisa teve como objetivo estabelecer um diálogo entre o processo de globalização, a transnacionalização das relações humanas, os seus impactos nos direitos humanos e trabalhistas e a possibilidade, diante da sua importância, de se reconhecer ou estabelecer uma jurisdição trabalhista transnacional.

A partir da leitura doutrinária especializada, foi possível constatar que o processo de globalização está avançando cada dia mais, representando uma modificação aparentemente se retorno para as relações humanas e sociais. Assim, seu impacto no trabalho e nos trabalhadores pode ser sentido e necessita de trato que levem em consideração essa realidade.

O efeito principal, nesse momento, é a transnacionalização das relações trabalhistas, o que faz com que todo e qualquer conflito que envolva direitos trabalhistas, portanto direitos humanos, necessitem de uma solução a nível também transnacional, o que acaba por refletir em algumas dificuldades causadas pela falta de preparo e previsão, dentro dos sistemas nacionais, de uma estrutura de mecanismos de solução de conflitos que atenda a essa necessidade que supera as barreiras da soberania nacional.

Entretanto, ainda que essa dificuldade seja observável e que ainda haja melhoramentos a serem feitos nesse sentido, o que se observa é que os sistemas nacionais, sendo o enfoque na pesquisa o caso brasileiro, estão se ajustando para receber essas demandas, mesmo que com as dificuldades representadas pela complexidade de definição de quais normas usar e como lidar com as imunidades internacionalmente reconhecidas.

Também foi possível constatar que, seja pela atuação de órgãos internacionais de proteção do trabalho, que não são dotados de jurisdição mas também pacificam conflitos, seja pela jurisdição emprestada em órgãos jurisdicionais transnacionais que tratam de matérias diversas porém conexas às questões trabalhistas, já é possível observar exemplos de jurisdição transnacional trabalhista.

Ainda assim, se mantém a necessidade de se envidar esforços na direção de criação de órgãos jurisdicionais transnacionais especializados em questões trabalhistas, visto que esta área, necessariamente indissociável da esfera econômica, foi, é e será muito impactada pela globalização e pela transnacionalização das relações humanas.

\section{REFERÊNCIAS}

ALVES, Danilo Scramin. A teoria geral do direito processual do trabalho: uma análise a partir do acesso à Justiça do Trabalho. Rio de Janeiro: Lúmen Juris, 2020. 
ÁVILA, Flávia de. A sistemática processual para a análise de casos perante o Sistema Interamericano de Proteção dos Direitos Humanos: ênfase em questões sociais. In: ORSINI, Adriana Goulart de Sena; ÁVILA, Flávia de; FANTINI, Karine Monteiro de Castro; SILVA, Nathane Fernandes da (Org.). Mecanismos de solução de controvérsias trabalhistas nas dimensões nacional e internacional. São Paulo: LTr, p. 213-225, 2015.

BARATTO, Márcia. Corte Europeia de Direitos Humanos e o trabalho. In: ORSINI, Adriana Goulart de Sena; ÁVILA, Flávia de; FANTINI, Karine Monteiro de Castro; SILVA, Nathane Fernandes da (Org.). Mecanismos de solução de controvérsias trabalhistas nas dimensões nacional e internacional. São Paulo: LTr, p. 261-273, 2015.

BAUMAN, Zygmunt. Globalização: as consequências humanas. Rio de Janeiro: Jorge Zahar Ed. 2001.

BERGER-WALLISER, Gerlinde. Reconciling Transnational Jurisdiction: A Comparative Approach to Personal Jurisdiction over Foreign Corporate Defendants in US Courts. Vanderbilt Journal of Transnational Law, vol. 51, no. 5, November 2018, p. 1243-1304. Disponível em: https://heinonline.org/HOL/P?h=hein.journals/vantl51\&i=1295. Acesso em 23 dez. 2020.

BICCA, Júlia Fragomeni; CRUZ, Paulo Márcio. Transnacionalismo e Sustentabilidade: Em Busca de um Globalismo Sustentável. Anais do evento VII Seminário Internacional de Construções Sustentáveis. Passo Fundo: IMED, 2018. Disponível em: https://soac.imed.edu.br/index.php/siet/isiet/paper/view/848. Acesso em 02 jan. 2021.

BRASIL. Supremo Tribunal Federal (2. Turma). Recurso Extraordinário 222368/PE. Imunidade de jurisdição. Reclamação trabalhista. Litígio entre estado estrangeiro e empregado brasileiro. Evolução do tema na doutrina, na legislação comparada e na jurisprudência do Supremo Tribunal Federal: da imunidade jurisdicional absoluta à imunidade jurisdicional meramente relativa. Recurso Extraordinário não conhecido. Os estados estrangeiros não dispõem de imunidade de jurisdição, perante o Poder Judiciário brasileiro, nas causas de natureza trabalhista, pois essa prerrogativa de direito internacional público tem caráter meramente relativo. Recorrente: Consulado Geral do Japão. Recorrido: Espólio de Iracy Ribeiro de Lima. Relator: Min. Celso de Mello, 28de fev. de 2002.

CAETANO, Fernanda Araújo Kallás e. A imunidade de jurisdição das organizações internacionais face ao direito de acesso à justiça. Revista de Direito Internacional, vol. 13, n. $3,2016, \quad$ p. 390-403. Available at: https://www.publicacoesacademicas.uniceub.br/rdi/article/view/4242/pdf. Access on Oct. 30, 2020.

CRUZ, Paulo Márcio; BODNAR, Zenildo. A transnacionalidade e a emergência do Estado e do Direito Transnacional. Revista Eletrônica do CEJUR, v. 1, n. 4, jan./jun. 2009, p. 10-20. Disponível em: https://revistas.ufpr.br/cejur/article/view/15054. Acesso em: 02 jan. 2021. 
DOOREY, David J. In Defense of Transnational Domestic Labor Regulation. Vanderbilt Journal of Transnational Law, vol. 43, no. 4, Out. 2010. Disponível em: https://heinonline.org/HOL/P?h=hein.journals/vant143\&i=959. Acesso em $23 \mathrm{dez} 2020$.

ESTENSSORO SAAVEDRA, Fernando. A geopolítica ambiental global do século 21: os desafios para a América latina. Santo Ângelo: Ed. Unijuí, 2019.

FERRER, Gabriel Real; CRUZ, Paulo Márcio. Os novos cenários transnacionais e a democracia assimétrica. Revista de Estudos Constitucionais, Hermenêutica e Teoria do Direito. v. 2, n. 2, p. 96-111, jul/dez. 2010. Disponível em: http://revistas.unisinos.br/index.php/RECHTD/article/view/442. Acesso em: 15 jan. 2021.

GARCIA, Marcos Leite. Direitos fundamentais e Transnacionalidade: um estudo preliminar. In: CRUZ, Paulo Márcio; STELZER, Joana (org.). Direito e Transnacionalidade. $2^{a}$ reimp. Curitiba: Juruá, 2011.

GIDDENS, Anthony. As conseqüiências da modernidade /Anthony Giddens; tradução de Raul Fiker. - São Paulo: Editora UNESP, 1991.

GIDDENS, Anthony. Sociology. 5th edition. Cambridge: Polity Press, 2006.

HILL, Flávia. O direito processual transnacional como forma de acesso à justiça no século XXI: os reflexos e desafios da sociedade contemporânea para o direito processual civil e a concepção de um título executivo transnacional. Tese (Doutorado em Direito) Universidade do Estado do Rio de Janeiro, Rio de Janeiro, 2013. Disponível em: http://www.bdtd.uerj.br/tde_busca/arquivo.php?codArquivo=5987. Acesso em 20 out. 2020.

JESSUP, Philip C. Direito transnacional. Tradução de Carlos Ramires Pinheiro da Silva. Editora Fundo de Cultura, 1965.

$\mathrm{KOH}$, Harold Hongju. Transnational legal process. Nebraska Law Review, v. 75, p. 181207, 1996. Disponível em: https://digitalcommons.law.yale.edu/fss_papers/2096/. Acesso em 23 dez. 2020.

LARA, Jaqueline Cordeiro de; GOULART, Rodrigo Fortunato. Conflitos de leis trabalhistas no espaço e o cancelamento da Súmula 207/TST. Revista eletrônica do Tribunal Regional do Trabalho da Bahia, Salvador, BA, v. 2, n. 2, p. 40-53, maio 2013. Disponível em: https://hdl.handle.net/20.500.12178/148210. Acesso em 2 nov. 2020.

LUPI, André Lipp Pinto Basto. A convenção sobre imunidade do Estado e seus bens e o direito brasileiro. Revista da Faculdade de Direito da UERJ, v.1, n. 19, jun./dez 2011. Disponível em: https://www.e-publicacoes.uerj.br/index.php/rfduerj/article/view/1784/1367. Acesso em 30 out. 2020.

MARTINS, Sérgio Pinto. Conflitos de leis trabalhistas no espaço e a circulação de trabalhadores. Revista da Faculdade de Direito, v. 94, p. 181-196, 1999. Disponível em: https://www.revistas.usp.br/rfdusp/article/view/67438. Acesso em: 23 dez. 2020. 
MOREIRA, Ana Júlia; FERREIRA, Marrielle Maia Alves. O trabalho escravo e o Tribunal Penal Internacional. In: ORSINI, Adriana Goulart de Sena; ÁVILA, Flávia de; FANTINI, Karine Monteiro de Castro; SILVA, Nathane Fernandes da (Org.). Mecanismos de solução de controvérsias trabalhistas nas dimensões nacional e internacional. São Paulo: LTr, p. 330-341, 2015.

MOREIRA, Teresa Coelho. Tribunal de Justiça da União Europeia e controvérsias trabalhistas. In: ORSINI, Adriana Goulart de Sena; ÁVILA, Flávia de; FANTINI, Karine Monteiro de Castro; SILVA, Nathane Fernandes da (Org.). Mecanismos de solução de controvérsias trabalhistas nas dimensões nacional e internacional. São Paulo: LTr, p. 298$308,2015$.

PIFFER, Carla. Transnacionalidade e imigração: a possibilidade de efetivação dos Direitos Humanos dos Transmigrantes diante de Decisões de Regresso na Itália e na União Europeia. 2014. Tese (Doutorado em Ciência Jurídica) - Universidade do Vale do Itajaí, Itajaí, 2014. Disponível em: http://siaibib01.univali.br/pdf/Carla\%20Piffer.pdf. Acesso em 02 jan. 2021.

PIMENTA, Raquel Betty de Castro. Organização Internacional do Trabalho - reclamações, queixas e procedimentos. In: ORSINI, Adriana Goulart de Sena; ÁVILA, Flávia de; FANTINI, Karine Monteiro de Castro; SILVA, Nathane Fernandes da (Org.). Mecanismos de solução de controvérsias trabalhistas nas dimensões nacional e internacional. São Paulo: LTr, p. 238-248, 2015.

PIOVESAN, Flávia. Direitos Humanos e Direito Constitucional Internacional. 14. ed. rev. São Paulo: Saraiva, 2013.

RIBEIRO, Jomara de Carvalho. A jurisdição da Corte Internacional de Justiça em casos de escravidão e trabalho forçado. In: ORSINI, Adriana Goulart de Sena; ÁVILA, Flávia de; FANTINI, Karine Monteiro de Castro; SILVA, Nathane Fernandes da (Org.). Mecanismos de solução de controvérsias trabalhistas nas dimensões nacional e internacional. São Paulo: LTr, p. 320-329, 2015.

SANTOS, Boaventura de Souza. Linha de horizonte. In: SANTOS, Boaventura de Souza. A Globalização e as ciências sociais. 2. Ed. São Paulo: Cortez, 2002.

SANTOS, Boaventura de Souza. Por uma Concepção Multicultural de Direitos Humanos. Lua Nova Revista de Cultura e Política, São Paulo, SP, n. 39, p. 107-124, 1997. Disponível em: $\quad$ https://www.scielo.br/j/ln/a/gVYtTs3QQ33f63sjRR8ZDgp/?format=pdf\&lang=pt. Acesso em 15 jan. 2021.

SANTOS, Maria Clara Oliveira; NICOLI, Pedro Augusto Gravatá. A proteção ao trabalho no Sistema Interamericano de Direitos Humanos. In: ORSINI, Adriana Goulart de Sena; ÁVILA, Flávia de; FANTINI, Karine Monteiro de Castro; SILVA, Nathane Fernandes da (Org.). Mecanismos de solução de controvérsias trabalhistas nas dimensões nacional e internacional. São Paulo: LTr, p. 249-260, 2015. 
SARLET, Ingo Wolfgang. Dignidade da Pessoa Humana e Direitos Fundamentais na Constituição Federal de 1988. Porto Alegre: Livraria do advogado, 2011.

SILVA, Roberto Luiz. A Organização Mundial do Comércio e as controvérsias sociais. In: ORSINI, Adriana Goulart de Sena; ÁVILA, Flávia de; FANTINI, Karine Monteiro de Castro; SILVA, Nathane Fernandes da (Org.). Mecanismos de solução de controvérsias trabalhistas nas dimensões nacional e internacional. São Paulo: LTr, p. 193-200, 2015.

SIMOWITZ, Aaron D. Legislating Transnational Jurisdiction. Virginia Journal of International Law, vol. 57, no. 2, Spring 2018, p. 325-382. Disponível em: https://heinonline.org/HOL/P?h=hein.journals/vajint57\&i=335. Acesso em 23 dez. 2020.

STELZER, Joana. O Fenômeno da Transnacionalização da Dimensão Jurídica. In: CRUZ, Paulo Márcio; STELZER, Joana (orgs). Direito e Transnacionalidade. $2^{\mathrm{a}}$ ed, p. 15-54. Curitiba: Juruá, 2011.

TRIBE, Laurence; DORF, Michael. Interpretando la constitución. Lima: Palestra, 2020.

VANDRESEN, Thaís; SOUZA, Maria Cláudia Antunes de. Globalization, Global Governance, and Challenges to Contemporary Constitutionalism: The (Trans) Constitutional Perspective and the Dialogue Among Jurisdictions. University of Baltimore Journal of International Law: Vol. 4, Article 2, 2016. Disponível em: http://scholarworks.law.ubalt.edu/ubjil/vol4/iss2/2. Acesso em 30 dez. 2020. 